\title{
Efficiency of the Sea Commercial Port Information System
}

\author{
Dmytro Zherlitsyn \\ Economic Cybernetics Dept., \\ National University of Life and \\ Environmental Sciences of Ukraine \\ Kyiv, Ukraine \\ http://orcid.org/0000-0002-2331-8690, \\ dzherlitsyn@gmail.com
}

\author{
Volodymyr Mandra \\ $\mathrm{CAO}$, \\ Metinvest SMC \\ Kryvyi Rih, Ukraine \\ http://orcid.org/0000-0002-4786-5744
}

\begin{abstract}
Information and decision support system is the most important part of each enterprise management process. The sea commercial port is a difficult business structure, which unites the functions of logistics operator, transport terminal, international gate and classical market agent. Therefore, they decision support system determines the specific efficiency principles of the managerial functions automatization. The observance of general and specific principles implies the initial theoretical justification of the sea commercial port needs. It proves, that the efficiency of the sea commercial port information system is based on general theoretical principles of building sustainable information systems, instrumental principles of certain business processes management, specifics of commercial ports and maritime operation management. The architecture of the sea commercial port decision support information system, which uses its efficiency principles, is proposed. They are presented as design and intellectual data collection methods, summary report generation instruments and so on. The five key stages for improving the efficiency of the sea commercial port decision support information system are improved. The paper shows that information system efficiency is evaluated by the general profitability and the partial indicators of value adding and cost saving for its structure elements.
\end{abstract}

Keywords-information system, sea commercial port, efficiency, efficiency principle, management process, decision support system

\section{INTRODUCTION}

\section{A. The problem formulation}

Information system is the most important part of the management process. The sea commercial port management system, that has a specific transport and cargo logistics, is not an exception. At the same time, the specifics of the sea commercial port activity are connected primarily with the necessity of organizing international transport and trade operations, that are imposed their requirements on the relevant information and decision support systems.

Implementation of the latest information technologies requires fundamental changes in the whole management process (metasystem, individual business processes and so on). Unfortunately, many Ukrainian business structures, which are involved into maritime transport chains, have problem with information support. For example, the Mariupol Sea Commercial Port uses more than 150 different applied software based on different principles, instruments and sources. On the other hand, every business element in the transport and logistics infrastructure and related business structures should apply electronic trading technology to respond promptly and to satisfy market and consumer requirements together with integration into world goods and financial markets, etc. Therefore, the problem of building the effective architecture of the information decision support system has great value for maritime business competitive.

\section{B. Background}

The basic principles of improving an enterprise information system are described in classic theoretical studies. V. M. Glushkov [1] and N. Wiener [2] are the founders of the basic principles of information systems automation. The other studies [3], [4], [5] are devoted to the latest methods of the information and analytical activity and further researches of information systems improvement. Special approaches (L. Guryanova, I. Nikolaiev, R. Zhovnovach at al. [6], Z. Schreiber [7], A. Robinson [8], S. Rowe and M.Pournader [9] etc.) have been presented by theoretical researches in the information technologies, economics and mathematical modeling in transport and logistics studies.

However, the specifics of the information and analytical technologies implementation, in terms of effective decisionmaking for Ukrainian transport and maritime companies, remains underdeveloped.

\section{Objectives of the Study}

The objective of this work is to study the latest specifics of the maritime information systems and to define the implementation efficiency principles and architecture of the decision support system of the sea commercial port. The specific objectives are:

- Understand new methods and approaches to electronic business in transport and logistics.

- Observe the latest information technologies in transport and maritime.

- Understand the classic principles of businessprocesses automatization.

- Identify specific components of the sea commercial port information system. 
- Propose the architecture of the sea commercial port decision support information system.

- Define the implementation stages of sea commercial port information system improvements.

\section{Abbreviations and Acronyms}

For the purposes of this study, the following abbreviations are used: SP - software package (SPs software packages); DSIS - decision support information system.

\section{THE LATEST FEATURES OF TRANSPORT LOGISTICS INFORMATION SYSTEMS}

\section{A. E-commence Features}

The forecasted volume of online sales by 2020 is almost 7 trillion USD, resulting in $27 \%$ of world trade in industrial products [10]. It has been proven that $68 \%$ of B2B buyers have a budget of more than 100 thousand USD [11]. Therefore, online platforms play an important role in procurement planning, product and supplier selection, even if products are not purchased online. This was stated by $94 \%$ of respondents and $71 \%$ of them underlined that as a result of such an internet search they have changed suppliers [10].

Therefore, freight forwarders and shippers are interested in online logistics services for these two schemes. Participants of the supply chain are strived to increase their competitiveness by introducing the latest information technologies, namely [8], [12], [13], [14]:

- Round-the-clock accessing to information on the geographic location of goods using GPS, GSM, Galileo, etc. geolocation equipment;

- Providing access to information regarding the quality of goods, their storage conditions, which are measured by sensors (temperature, humidity, integrity, packaging, impact);

- Using robotic technologies for sorting, packing, forming pallets, loading and unloading and other operations;

- Data sharing on the actual state of objects in the supply chain, synchronization of databases (information systems);

- Big Data Processing, analytical data sharing based on the methods of regression analysis, time series analysis, simulation models, scenario analysis methods, routing methods, bandwidth adjustment model, etc.;

- Supporting of websites, blogs and pages (groups) in social networks for visibility and recognition, as well as gathering information about participants in the supply chain (reviews, ratings, offers, prices).

Thus, shippers are considering online forwarding services and ordering on the site as an instrument to have faster and timely access to the required information. However, these entities significantly lose their time because of the number of unresolved issues. Therefore, the electronic commerce of logistics services needs to be substantially improved and considered as an essential direction for the implementation of innovative sea commercial management instruments.
On-line sales for the logistics services are the promising direction for the development of transport and cargo systems. They can be carried out according to the following schemes [7], [15]:

- Integration with e-commerce providers to deliver onsite instruments for instant pricing and routing for vendors;

- Internet sales. The use of website by logistics provider, potential and existing customers can instantly compare and select (order) freight transportation and handling services.

\section{B. Data Science and Machine Learning Instruments}

Data Science and Big Data methods are the modern trends of innovation management [16]. Big Data Analysis models and tools are used to support integrated business process planning, enabling business entities for better understanding of trends in the logistics and commodity markets, as well as the demands, intentions and desires of customers, including end-users of goods. At the same time, this allows to create a supply chain that responds faster to changes (events) in the business environment and quickly adapts to new business conditions.

In some theoretical researches [9], [15], this concept reflects the creation of a chain called the "responsive supply chain". Internet of Things (IoT) and machine learning instruments are currently used to plan asset movements (changes) to avoid unplanned downtime [3]. IoT provides real-time telemetry data to get detailed information about production and logistics processes. The machine learning algorithms are used to process actual data, to predict nonoperating states of machines, equipment and other means, etc.

\section{ARCHITECTURE OF THE SEA COMMERCIAL PORT DECISION SUPPORT INFORMATION SYSTEM}

The most commonly used automation systems, that fully or partially implement the principles and the latest approaches, are: SAP, Oracle E-Business Suit, Microsoft Dynamics, 1C ERP Enterprise Management [17]. These automated systems are determined by their sufficient functionality and versatility; however, their implementation and maintenance require significant supporting costs from the sea commercial port. This matter is largely a prerequisite for the own systems development or for the implementation of sectoral developments within the framework of finished information products.

\section{A. Modern Approaches in the Information Area}

The key risks, which are associated with the widespread use of the different SPs (which integrate many functions, manufacturers and assignments), are determined by the following features of the Black Sea maritime region and international market of information products:

- The presence of the large number of complex sharing data (various formats, indicators, units of measure);

- The availability of SPs with different functions that require additional organizational support for the systematization and initial processing of management information; 
- The necessity to coordinate information flows in time and space (for example, technological information is formed on a continuous basis, financial information is tied to working hours, etc.), which complicates the possibility of using appropriate management information;

- The need in close interaction between operational specialists (transport, production, logistics, finance) with specialists in information technology, economic and mathematical modeling for timely detection of operational problems and harmonization of relevant regulatory measures;

- The need to implement an innovative approach to the processes of collecting, processing and using managerial information. For example, using the typical solutions that provide classical SPs is possible only for a part of business processes (deterministic processes or other predictable processes). However, in order to quickly solve the problems of the continuity of management processes, the own developments, generalizations, and proposals are needed.

Therefore, contemporary information systems of the sea commercial port should meet the basic principles [1], [2], [18]:

- workflow automation (involve closing most of the information flows between individual control systems directly through the computer);

- integral information base (focuses on creation of a single administrative task for the primary database with a minimum of redundancy, which is a prerequisite for the database maintenance and integrity);

- one-time data entry (defines one of the optimal criteria of the general control system and makes it possible to repeatedly reuse of the primary and processed information);

- dynamic integrity (ensures correctness of any modifications of managerial information and the mutual conformity of any of its parts and local implementations);

- $\quad$ system unity (involves the obligatory elaboration and harmonization of all elements of the information system);

- universality and unification (assume the availability of individual features of specific automated workplaces that should not be rigidly laid into the software);

- modularity (provides conditions for a relatively easy adaptation of the system to changing conditions by each module development and improvement).

The basic principles do not lose their relevance in the current conditions of rapid development of automated control systems, as well as methods of preparation, approval and supporting of managerial decisions [18]. Their practical implementation requires consideration of both the instrumental and sectoral features of the information systems of specific sea commercial port.

\section{B. Features of the Operational Processes of the Sea Commercial Port}

The diversity of activities and forms of organization within modern sea commercial ports, their functions and persecuted purposes, creates a variety of possible information, control, analytical and managerial interactions. In this regard, the interest and practical value has the analytical review of the most usable and multifunctional external information flows. They are used by world seaports as a basic component of their own managerial systems in regard of necessary information and analytical managing instruments (Fig. 1).

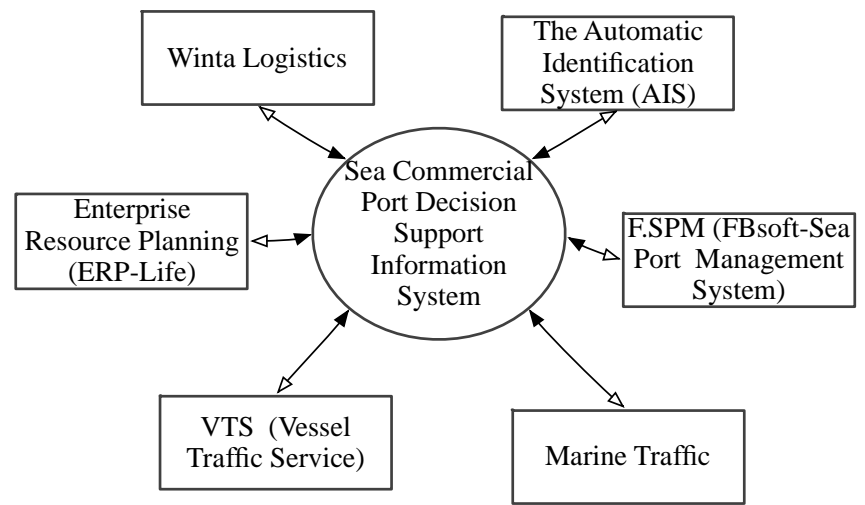

Fig. 1. Key external technological information subsystems of the sea commercial port information flow

Subsystem 1. Enterprise Resource Planning (ERP-Life). Functions of the subsystem 3.1. include the support of the sea commercial port main activity management processes as a participant in the national transport and cargo system and the enlarged supply chains, namely, the management of the cargo movement.

Subsystem 2. Winta Logistics or management of auxiliary and associated business processes. This objective becomes especially relevant to the application of the methodology of constructing transport and logistics complexes based on the sea commercial ports infrastructure.

Subsystem 3. The Automatic Identification System or the system of identification and data sharing.

Subsystem 4. The FBsoft-Sea Port Management System or the management of marketing and sales activities of the sea commercial port.

Subsystem 5. Marine Traffic or traffic management system.

Subsystem 6. Vessel Traffic Service or vessel traffic management services.

\section{Architecture of the Sea Commercial Port Decision Support Information System}

The general architecture of the information system of DSIS of the sea commercial port (Fig. 2), based on previous research and results presented in [13], [15], [17], [18], can be proposed. The Fig. 2 shows the framework of the information DSIS of the sea commercial port implementation that can be presented by the following five stages. 


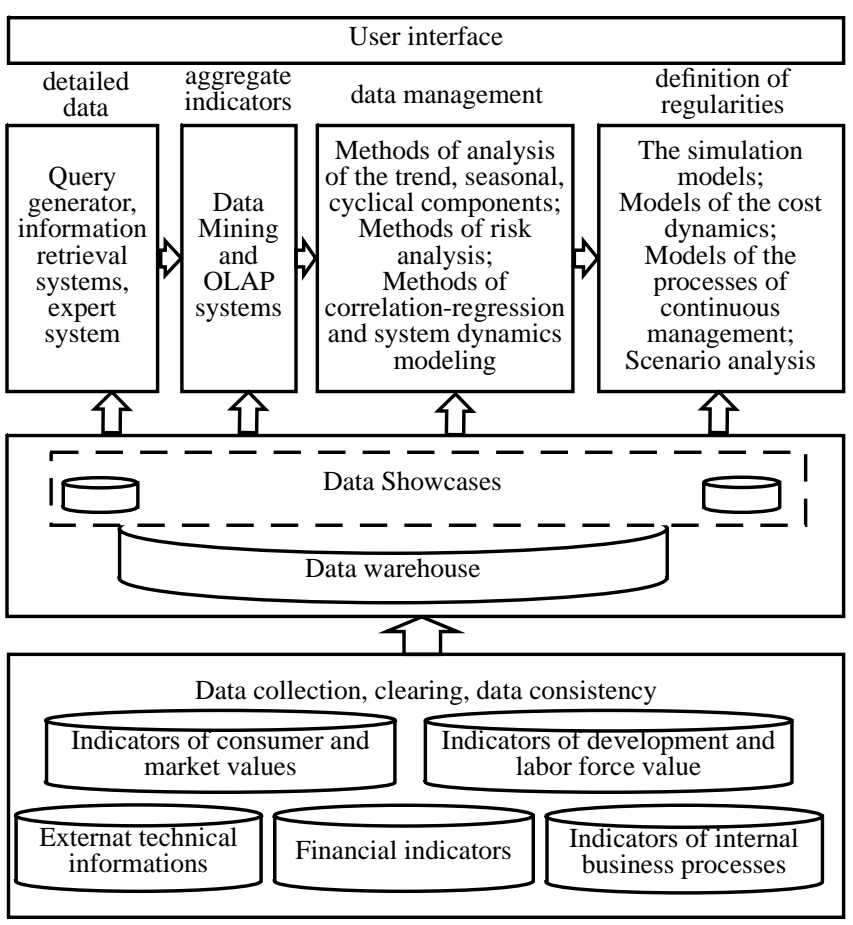

Fig. 2. Architecture of the Sea Commercial Port DSIS (the authors result, which is based on studies [4], [5], [12], [13])

Stage 1. Designing stage. Setting objectives of the sea commercial port DSIS implementation.

Stage 2. Collection, cleaning, data coherence. The result of this stage is the creation of a data warehouse of the DSIS based on internal and external data sources. The data warehouse should contain a complete set of information necessary for decision-making and be cleared from the thirdparty data.

Stage 3. Information and analytical modeling. As it is shown, the stage 3 of the sea commercial port DSIS architecture (Fig. 2) can be divided into two substages.

Substage 3.1. Formation of the detailed data. In the most cases, relational databases perfectly deal with this task. The generally accepted standard of language for manipulating relational data is SQL. Information retrieval systems, that provide the end-user with interface, in the tasks of searching for detailed information can be used as add-ons for both individual data processing systems and over the data warehouse in general [4, p.12-18].

Substage 3.2. Formation of the aggregate indicators. It occurs due to the use of OLAP, which involves the presence of a component of multivariate analysis and expands the functionality of relational database systems.

Stage 4. Creation of the forecast estimates and scenarios. This stage in the sea commercial port DSIS is also presented by two substages.

Substage 4.1. Data management. At this stage, the establishment of interconnections between indicators is carried out; forecasting is carried out and deviations of predicted values are studied. The verification procedure is carried out, information and prognostic suitability of the models is determined; regression models are corrected.
Substage 4.2. Management of laws. The result of this stage is the choice of one or another control lever based on scenario analysis.

Stage 5. Generation of the summary documents and proposals. They are implemented in the user interface based on the results obtained at the Stage 4 and the rules laid down in the system.

\section{EFFICIENCY INDICATORS OF THE SEA COMMERCIAL PORT DECISION SUPPORT INFORMATION SYSTEM}

The architecture of the sea commercial, which has been proposed early, defines general direction to estimate the efficiency indicators for the sea commercial port decision support information system. The common results of the information system improvement can be evaluated by the performance indicators, such as: relative administrative costs, earnings before interest and tax (EBIT) or related profitability, value added (VA) rates etc. These indicators are used in the dynamic aspect. Therefore, the common efficiency of the sea commercial port can be evaluated by the next expression:

$$
E=\frac{\partial q(c, t)}{\partial t}+\frac{\partial p(q, t)}{\partial t}
$$

where $E$ - the general effect of DSIS improvement, $q(c, t)-$ sales function of costs $(c)$ and time $(t)$ variables, $p(q, t)-$ profits function of sales $(q)$ and time $(t)$ variables.

The Fig. 2 shows, that the sea commercial port decision support information system is divided into separated subsystems. Each of that subsystems have related efficiency indicator or set of indicators. It can be shown by the next efficiency groups.

- Market and consumer results are estimated by the efficiency of this business processes and level of customer satisfaction. The main estimated results of this effect are the sales and structure of sales.

- Efficiency for the operational management processes can be estimated by value and time related indicators. The value-related indicators are different assets turnover or derivative of the information volume, etc. The same partial effects were studied in [19] and [20].

- Effects of the increase work force productivity, which are caused by improving the DSIS, are evaluated by the administrative payroll expenses, changes in the information volumes and the related managerial quality level.

- The results of the internal and external information usage are estimated as effect of infrastructure quality. The same effect, for example, is shown in the World Bank Report "International Logistics Performance Index" [21].

The subsystems effects are not the same indicators, but their dynamics can be estimated by the classical principal (1) or by using partial derivative by the profit, sales and expense functions for specified efficiency factors. 
Therefore, the efficiency of the sea commercial port decision support information system has a complex concept. It should be evaluated by the common effect and partial results of related managements systems and processes.

\section{CONCLUSION}

The sea commercial port DSIS architecture uses the instruments of analytical information processing, economic and mathematics modeling and scenario analysis and allows to improve the quality of sea commercial management system within the framework of a balanced scoring system, logistics operation indicators and supply chain management methods. It includes the specific tools of databases, models and knowledge, requirements for information generated within showcases and data warehouses. There are five key stages for the implementation of the sea commercial port DSIS improvements, proposed in the paper. They are common architecture design; collecting, cleaning, reconciling data; informational-analytical modeling (formation of detailed data; formation of aggregate indicators); creating of estimates and scenarios (data management and regularity management); generating offers and summary documents that are implemented in the user interface. The key efficiency indicators of the sea commercial port DSIS can be defined as relative administrative costs and profitability of intangible assets and capital of a seaport. Partial effects are estimated by the results of the related subsystem. They are market, labor force, operational management and information quality results. While choosing an instrumental solution, particular attention should be paid to the overall cost of the DSIS improvements implementation, as well as the availability of the program extension within the sectoral specifics of the operation of sea transport. Implementation of the paper's results into the sea commercial port activities has wide spheres of use. For example, it can be used to form the information base for a balanced scorecard within the intellectual methods of trend, seasonal, cyclical components together with cluster analysis, methods of assessing and forecasting risks of financial and economic activity of a seaport, results of the use of correlation-regression and system-dynamic modeling. Further research should be carried out for choosing the applied instruments for the implementation of the main technical and economic methods to analyze the effectiveness of the DSIS instruments and proposed theoretical approaches implementation.

\section{REFERENCES}

[1] V. M. Glushkov, Fundamentals of Paperless Informatics [Osnovy bezbumazhnoj informatiki] (in Russian), Moscow: Science. The main edition of physical and mathematical literature, 1982.

[2] N. Wiener, Cybernetics, NY: John Wiley \& Sons, (in English), 1948 [Online]. Available: https://ieeexplore.ieee.org/stamp/stamp.jsp?tp=\&arnumber= 568739 . Accessed on: June 11, 2019.

[3] J. LaRiviere, P. McAfee, J. Rao, V.K. Narayanan, and W. Sun, "Where Predictive Analytics Is Having the Biggest Impact" (in English), Harvard Business Review, 2016 [Online]. - Available: https://hbr.org/2016/05/where-predictive-analytics-is-having-thebiggest-impact. Accessed on: June 11, 2019.

[4] L.V. Shhaveljov, "Methods of analytical data processing for decision support" [Sposoby analiticheskoj obrabotki dannyh dlja podderzhki prinjatija reshenij] (in Russian), Database management systems, No 4-5, 1998 [Online]. - $\quad$ Available: http://infovisor.ivanovo.ru/press/paper04.html. Accessed on: June 11, 2019

[5] I.V. Zakharova, and L.Ya. Filipova, Fundamentals of information and analytical activity [Osnovy informacijno-analitychnoyi diyal'nosti] (In Ukrainian), Kyiv: Center for Educational Literature, 2013.

[6] L. Guryanova at al. "Modeling of the enterprise functioning stability using the automatic control theory apparatus". Eastern-European Journal of Enterprise Technologies, No 3(88), Vol. 4, pp. 45-55, 2017.

[7] Z. Schreiber, State of Online Logistics Sales 2015. Opportunities in B2B Logistics ecommerce (in English). Freightos, 2016.

[8] A. Robinson, "The Digital Supply Chain: The Landscape, Trends, Types, and the Application in Supply Chain Management" (in English), Cerasis, 2017 [Online]. - Available: http://cerasis.com/2017/ 06/05/e-book-digital-supply-chain/. Accessed on: June 11, 2019.

[9] S. Rowe, and M. Pournader, "Supply Chain Big Data Series Part 1" (in English), KPMG, 2017. [Online]. - Available: https://assets.kpmg.com/content/dam/kpmg/au/pdf/2017/big-dataanalytics-supply-chain-performance.pdf. Accessed on: June 11, 2019.

[10] UNCTADStat "Merchandise: Total trade and share, annual, 19482015", (in English), 2015 [Online]. - Available: http://unctadstat.unctad.org/wds/

/TableViewer/tableView.aspx?ReportId=101. Accessed on: June 11, 2019.

[11] UNCTADStat. "Container port throughput, annual, 2008-2014", (in English), 2014 [Online]. - Available from: http://unctadstat.unctad.org/wds/TableViewer/tableView.aspx?Report $\mathrm{Id}=13321$. Accessed on: June 11, 2019.

[12] R. Elbert, H. Pontow, and A. Benlian, "The role of interorganizational information systems in maritime transport chains," (in English), Electronic Markets, Article vol. 27, no. 2, pp. 157-173, May 2017, doi: 10.1007/s12525-016-0216-3.

[13] L. Heilig, and S. Voss, "Information systems in seaports: a categorization and overview," (in English), Information Technology \& Management, Article vol. 18, no. 3, pp. 179-201, Sep 2017, doi: 10.1007/s10799-016-0269-1.

[14] A. Palazov et al., "Black Sea Observing System," (in English), Frontiers in Marine Science, Review vol. 6, p. 8, Jun 2019, Art no. Unsp 315, doi: 10.3389/fmars.2019.00315.

[15] S. Sinesi, M.G. Altieri, M. Marinelli, M. Dell'Orco, and Ieee, "A multivariate logic Decision Support System for optimization of the maritime routes," (in English), 2017 5th Ieee International Conference on Models and Technologies for Intelligent Transportation Systems (Mt-Its), Proceedings Paper pp. 75-79, 2017.

[16] D. Yang, L. X. Wu, S. A. Wang, H. Y. Jia, and K. X. Li, "How big data enriches maritime research - a critical review of Automatic Identification System (AIS) data applications," (in English), Transport Reviews, Review; Early Access p. 19, doi: 10.1080/01441647.2019.1649315.

[17] Yu.H. Lysenko et al., Modernization of financial systems: methodology and management tools [Modernizatsiia finansovykh system: metodolohiia ta instrumenty upravlinnia]. (in Ukrainian), Poltava, Ukraine: PUET, 2017.

[18] V.V. Mandra, Modernization of sea commercial port management processes: methodology, models and methods [Modernizatsiia protsesiv upravlinnia morskym torhovelnym portom: metodolohiia, modeli ta metody]. (in Ukrainian), Poltava, Ukraine: PUET, 2018.

[19] R. H. M. Emmerink, E. T. Verhoef, P. Nijkamp, and P. Rietveld, "Information effects in transport with stochastic capacity and uncertainty costs," (in English), International Economic Review, Article vol. 39, no. 1, pp. 89-110, Feb 1998, doi: 10.2307/2527232.

[20] M. Hajder, J. Kolbusz, and T. Bartczak, "Cost Models for Life-Cycle Phases of Information Systems," in 6th International Conference on Human System Interactions (HSI), Gdansk, POLAND, Jun 06-08 2013, NEW YORK: Ieee, in Conference on Human System Interaction, 2013, pp. 231-234.

[21] Global Rankings 2018. Logistics Performance Index (in English), 2018 [Online]. - Available: https://lpi.worldbank.org/international/global Accessed on: June 11, 2019. 